\title{
Impact of Industrial SMEs in the Environment Conservation : A Systematic Mapping Study
}

\author{
Carlos Leonidas Yance Carvajal ${ }^{\mathrm{a} 1}$, Joan Carles Gil ${ }^{\mathrm{b}}$, Angela Díaz Cadena ${ }^{\mathrm{c}}$, Juan Calderón Cisneros ${ }^{\mathrm{a} 2}$, \\ Miguel Botto-Tobar ${ }^{\mathrm{d}, \mathrm{e}}$, Félix Enrique Villegas Yagual ${ }^{\mathrm{a}}$ \\ ${ }^{a}$ Universidad Estatal de Milagro, Km 1,5 vía Km 26, Milagro, Ecuador \\ E-mail: ${ }^{1}$ cyancec@unemi.edu.ec; ${ }^{2}$ jcalderonc@unemi.edu.ec; ${ }^{3}$ fvillegasy@unemi.edu.ec \\ ${ }^{b}$ Universidad Politécnica de Catalunya, Campus Nord, Carrer de Jordi Girona, 1, 3, Barcelona, Spain \\ E-mail: joan.carles.gil@upc.edu \\ ${ }^{c}$ Universitat de Valencia, Camí de Vera s/n, 46022 València, Spain \\ E-mail: angela.ad949@gmail.com \\ ${ }^{d}$ Eindhoven University of Technology, 5600 MB Eindhoven, The Netherlands \\ E-mail:m.a.botto.tobar@tue.nl \\ ${ }^{e}$ University of Guayaquil, Cdla. Universitaria “Salvador Allende”, Guayaquil, Ecuador \\ E-mail:miguel.bottot@ug.edu.ec
}

\begin{abstract}
Small and medium-sized companies have an impact on the environment where they operate. In some cases, the effects on the environment can be significant within local communities leading to a series of negative processes, such as emission pollution into the atmosphere, the discharges to rivers and seas, the production of waste; in some cases, it makes the contamination to the soil. This paper presents the results of the systematic mapping study aimed at assessing environmental management in industrial SMEs. Descriptive studies of SMEs emphasize their poor environmental commitment, describing them as primarily interested in controlling pollutant emissions just to comply with regulations. Ninety-eight papers were identified, and the results indicate that environmental management is not fully incorporated as a standard in the management processes of SMEs, so their environmental performance depends on the degree of pressure placed by control agencies, authorities, or clients. Such companies believe that the economic resources allocated for environmental care are costs rather than investments. However, research on environmental management in SMEs shows the uniformity of environmental strategies with a low level of development. The intellectual interest arose based on the need to identify the environmental needs that small businesses in developing countries must attend. The paper is justified by its own condition of proposing sustainable development, with the possibility of providing a real vision of the situation of industrial businesses in environmental matters.
\end{abstract}

Keywords - SMEs; eco-efficiency; environmental strategy; sustainability development.

\section{INTRODUCTION}

Environmental problems are closely linked to development models and socioeconomic structures. The dilemma of our time is to balance the satisfaction of human needs and aspirations with maintaining biophysical and social systems because their sustainability is critical to life on the planet [1]. Currently, the search for sustainable development is more visible. It needs the incorporation of economic, social, and environmental elements [2]. Environmental problems are closely linked to development models and socioeconomic structures. The dilemma of our time is to balance the satisfaction of human needs and aspirations with maintaining biophysical and social systems since sustainability is critical to life on the planet [1].

Sustainability is in the focus of the discussions about the development objectives. There is an awareness that protecting the environment is a necessary and essential condition for the survival of the planet. Countries are generally determined to find solutions to sustainability problems, which has led to the establishment of sustainable ventures that also contribute to the sustainability of the environment in which they are developed. The sustainability of SMEs is essential to achieve the strategic objectives of the 
business [3]. As a result, a new generation of entrepreneurs has emerged who seek to solve sustainability problems, develop their imagination, and apply their creativity to develop prototypes and create solutions of environmental, social, and economic value [4].

People who can master new technologies quickly will be competitive [5]. Today for almost any niche of business is characterized by an extremely high level of competition. To not only survive in this environment and to take a competitive position, but companies also must continually evolve, adopting international best practices, mastering new technologies, expanding the scope of activities. Sustainable competitive operation of any modern enterprise is possible only in case of its modernization, active, and comprehensive extension activities and the use of the latest technologies, both in production and in management [6].

The objective of this research is to determine the incidence of industrial SMEs in environmental conservation in the province of Guayas, Ecuador, to establish a diagnosis that allows generating a sustainable development proposal, and contribute to finding solutions of environmental, social, and economic value for the region.

The development of cities, industries, and lately, civilization causes a series of situations that deteriorate the ecosystem. The behavior of SMEs has been very heterogeneous, and these companies have had different motivations and challenges. Some SMEs have made great progress in environmental care processes and social responsibility strategies [7]. Besides, in the literature, there has been an insufficient emphasis placed on the specific competencies that firms should develop to facilitate the adoption of environmental protection practices, especially the collaboration with other firms and product innovation [8]. In short, it is necessary to study the environmental performance of SMEs in particularly complex contexts of competition, such as those of OERs. These kinds of contexts can influence the organizational and management features that explain SMEs'. However, some SMEs do not comply with environmental control because they do not know the regulations or their impact on the environment. This problem's solution is of particular significance for the areas of intensive anthropogenic influence with the local concentration of mining and ore-processing industries [9]. Smaller companies are the least compliant due to financing limitations and informal techniques.

The identification of environmental aspects and the evaluation of the effects associated with a business or industrial activity is essential for determining the environmental impact caused by activities, products, or services, and for setting environmental objectives and goals. The analyses of the environmental management of companies are of great importance, considering their multiple dimensions. However, this type of study is scarce in SMEs [10].

It is necessary to determine the peculiar features of SMEs and their efforts to address environmental management problems. SMEs are organizations with limited financial resources for the care environment, the lack of these resources restricts the development of initiatives to preserve the environment [11]. Ortiz et al. believed that the assessment of the product lifecycle (LCA) in SMEs is needed not only to meet the demands of consumers for environment-friendly products but also to help build green markets. Nevertheless, there are still no studies of this type in developing countries [12].

Aragón-Correa et al. presented the impacts on the environment and strategies that organizations use to reduce them, showing that SMEs can adopt proactive practices that can favor their financial performance [13]. Future research should study the internal aspects that may affect the environmental behavior of institutions, LePoutre et al. analyzed the correlation of the size and business behavior of companies and concluded that due to their lack of power, most SMEs do not recognize the problems of social responsibility [14]. They indicate that the internal and external factors of SMEs influence the behavioral processes of social responsibility yet remain to be investigated and proposed to build a green power plant to explore its positive effects on the innovative activity of companies. The results showed that it had a positive effect on the innovative production of organic products by SMEs. Future research should focus on green innovation and environmental management.

Torugsa et al. identified antecedents and organizations' characteristics to develop a model of elements that influence the decisions of these organizations. The results showed that small businesses do not have business plans formalized (in writing); their funds tend to depend on family loans. However, researchers should still consider the difference in the conditions of financing decisions and factors that may be subject to specific family variables [15].

Aragón et al. presented the correlation between the size of organizations and their ability to respond to environmental pollution. The results indicated that SMEs managers should acquire more knowledge about sustainable development and allocate more resources to deal with environmental impacts. Also, the authors suggested that it was necessary to conduct a cross-sectional study that would include multiple dimensions of the environment and expand the sampling scope to see if the results of this research remain consistent [16].

Van Hemel et al. studied the behavior of ecological design in SMEs. The results of their study showed that internal elements seem to have a more significant influence than external elements in making decisions about environmental care. The organizations took environmental factors into account in their search for business objectives. The option to improve environmental management is an opportunity if it is backed by incentives other than environmental benefit [17].

Mahlia et al. studied energy storage and the ability to improve system performance, to replace residual fuel in the electricity grid and transport without neglecting other sectors [18]. Anggadwita et al. analyzed the practices of socially responsible behavior adopted by SMEs and the associated difficulties they experienced. They indicated that. SMEs adopt various social responsibility practices that focus mainly on their suppliers' employees. The development of future research on SMEs must include various criteria, such as the use of informal systems to transfer social responsibility to suppliers [19]. 
Gadenne et al. examined how the existing and potential stakeholders influence the environmental awareness, attitudes, and behaviors of SME owners. The results indicate that the lack of financial resources is a significant factor preventing SME owners/managers from learning environmental practices. However, future research should analyze beliefs about the environment as of their commercial attitudes [20].

The reasons for each company to care about the environment may be different, depending on its size, its international presence, or its ethical values [21]. Undoubtedly, the primary motivation is mandatory compliance with environmental regulations. Moreover, the change in the attitude of some businesspersons and the application of clean technologies are also associated with the intention to avoid being penalized. In the past, in many cases, it was much cheaper for a company to pay a fine than to make the necessary environmental investments.

Nevertheless, it seems that the laws of the market impose the most significant change in attitude. That is to say; it can be observed in many countries a growing conviction on the part of people in a business that competitiveness in national and international markets is closely linked to their environmental performance. Analysts agree that companies that do not respect the environment and those whose production is not environmentally sustainable will be excluded from international markets. The challenge is to make production processes and competitiveness compatible with respect for the environment. Thus, part of the business community is embarking on the path towards cleaner production. It refers to the efficient use of natural resources and the lower generation of waste from economic and industrial activity.

\section{MATERIALS AND METHOD}

A systematic study of literature was carried out considering the research works previously carried out [13]. A systematic study allows us to organize and summarize the existing information that is related to the investigation; this is carried out through three-stage: Planning, execution, and reports.

\section{A. Planning Stage}

This stage includes the following activities to create the review of research and previous writings: (1) definition of research question; (2) development of search strategy; (3) location of primary studies; (4) quality control; (5) determination of data extraction strategy; and (6) synthesis methods selection.

\section{B. Research Question}

The objective of the systematic study is to examine the incidence of industrial SMEs in the environment, based on the following research question: What factors induce the industrial SMEs to care properly for the environment? The research question has been divided into more detail questions: RQ1: What is the degree of participation of industrial SMEs in the strategies aimed at mitigating the environmental impact? RQ2: What sources of financing are necessary for the industrial SMEs to carry out ecological initiatives? RQ3: What is the level of leadership in the environmental training of industrial SMEs? RQ4: What is the level of environmental training for employees of the Industrial SME?

\section{Search Strategy}

The databases that were used for the primary studies were Scopus and Web of Science. To perform the search in the selected databases, a search string was used (see Table I). The revised period included studies and research published between 2000 and 2018. This start date was chosen because 2000 was the year when it began to appear in the field of sustainability of industrial SMEs.

\section{Selection of primary studies}

The result of this search was evaluated with the objective of including its inclusion or not (considering the title, summary, and keywords). Research and article that meet at least one of the following inclusion criteria were chosen: (1) documents that present sustainable development in the industry; (2) documents that present empirical studies, case studies or experiments that are related to environmental sustainability.

TABLE I

APPLIED SEARCH

\begin{tabular}{|l|l|l|}
\hline Concept & Alternative terms & \\
\hline Sustainability & ("INDUSTRIAL SMEs" OR & AND \\
& "CORPORATE SUSTAINABILITY") & \\
\hline & $\begin{array}{l}\text { Eco-efficiency OR "Environmental } \\
\text { Strategy" OR "Sustainable } \\
\text { Development" }\end{array}$ & \\
& & \\
\hline
\end{tabular}

Research papers that met at least one of the criteria written below were excluded:

- Papers presenting special numbers.

- Duplicate of study or research from different sources.

- Papers with few pages.

- Papers not written in a language other than English or Spanish.

\section{E. Quality evaluation}

To evaluate the quality of the selected studies, a threestatement Likert scale questionnaire was designed:

- The environmental sustainability strategies of SMEs.

- Publication in relevant journals.

- Referenced by other authors.

\section{F. Data extraction strategy}

This is based on a possible set of answers to each research question. The answers to each question are explained below. For RQ1 (strategies used to mitigate environmental impacts), the following extraction criteria $\mathrm{C} 1-\mathrm{C} 3$ were used:

1) C1: As for environmental impact mitigation, two strategies were considered, the firs strategy is conventional if the document uses environmental mitigation.

- Preventive measures: Set of provisions and activities previously designed, with the aim of avoiding a negative effect on the environment.

- Reduction or mitigation measures: It is the set of actions to be implemented once the impact and its 
magnitude are identified to minimize the effects of this impact as much as possible.

- Compensation measures: These are applied when the impact is considered inevitable despite the implementation of mitigation measures.

The second strategy to be considered in environmental impact mitigation is development model:

- Air quality protection measures.

- Noise control measures.

- Soil quality protection measures.

- Proper waste management measures.

- Erosion control measures.

- Water quality protection measures.

- Flora protection, conservation, and relocation measures.

- Wildlife rescue measures.

2) C2: Approaches to mitigate environmental impacts consists of three mitigation approaches [22]. The first approach is good practices emphasize that mitigation is through good environmental practices. The second is the policy that highlights mitigation through various environmental policies and/or changing the configuration of procedures, such as:

- Integrated water management policy.

- Urban habitat protection policy.

- Environmental education policy.

- Forest policy and forest development plan.

- Cleaner production policy.

- Waste use and management policy.

- Soil protection policy.

- Wildlife protection policy.

The third is a code of behavior that modification of the existing codes of behavior to support environmental care is based on the analysis of environmental impacts.

3) C3: Environmental care model: the implementation of a win-win model [23] was considered:

- Private: Includes the active participation of private institutions in promoting environmental care.

- Community: Includes the joint involvement of SMEs and the community in environmental protection activities.

As for RQ2 (Sources of financing are necessary for the industrial SMEs to carry out ecological initiatives [24] (C4):

4) C4: Sources of financing:

- Public: if the document shows that public institutions support by means of loans or economic aid to enable SMEs to mitigate the environmental impact.

- Private: incentives and grants received by SMEs from private institutions interested in environmental care.

For RQ3 (Level of training in environmental matters for managers of Industrial SMEs), the following responses were considered as (C5).

5) (C5):

- Planned: if they present a management system for SMEs, environmental training plans for their owners and managers.
- Informal: The owners and managers train themselves in environmental care through websites, books, magazines.

Finally, for RQ4 Level of environmental knowledge of employees of industrial SMEs, the following under the extraction criteria was considered C6-C7:

6) C6: Phase(s), on which the studies are based: one or more eco-efficient processes through the environmental training of its staff [25]:

- Requirements: if SMEs run courses based on the needs of the environment.

- Process: if the environmental training is part of the process of sustainable development of SMEs.

- Community: if the environmental training is carried out jointly with the community directly affected.

7) C7: means involved:

- Technological: the means used for environmental training include technological means (e.g., computer systems).

- Regulations: environmental training is part of the environment protection regulations and policies of SMEs.

\section{G. Synthesis method}

In this research, a quantitative and qualitative method was applied. The quantitative part was based on:

- Quantify the number of respondents with primary studies.

- Quantify the articles that relate to the topic to be investigated.

The qualitative part was based on several representative studies, results of the quality assessment.

\section{H. Conducting stage}

The literature review showed the following result (See Table II): 98 articles were selected, according to the inclusion criteria.

TABLE II

Results OF The CONDUCTING STAGE

\begin{tabular}{|l|c|c|}
\hline \multicolumn{1}{|c|}{ Source } & $\begin{array}{c}\text { Possible } \\
\text { article }\end{array}$ & $\begin{array}{c}\text { Select } \\
\text { article }\end{array}$ \\
\hline Journal of Cleaner Production & 213 & 23 \\
\hline Sustainability & 123 & 17 \\
\hline Business Strategy and The Environment & 106 & 14 \\
\hline Journal of Business Ethics & 92 & 12 \\
\hline $\begin{array}{l}\text { Corporate Social Responsibility and } \\
\text { Environmental Management }\end{array}$ & 72 & 9 \\
\hline Sustainable Development & 42 & 7 \\
\hline Organization Environment & 20 & 5 \\
\hline $\begin{array}{l}\text { International Journal of Production } \\
\text { Economics }\end{array}$ & 16 & 4 \\
\hline Ecological Economics & 16 & 3 \\
\hline $\begin{array}{l}\text { International Journal of Sustainable and } \\
\text { Word Ecology }\end{array}$ & 13 & 2 \\
\hline $\begin{array}{l}\text { European Journal of Sustainnable } \\
\text { Development }\end{array}$ & 11 & 2 \\
\hline \multicolumn{1}{|c|}{ Total } & 724 & 98 \\
\hline
\end{tabular}




\section{RESULTS AND DISCUSSION}

The general results based on the primary studies are classified in each of the research responses, presented in Table III.

\section{A. Environmental mitigation strategy}

The criterion $\mathrm{C} 1$ (environmental mitigation strategies) revealed that about $11.71 \%$ of the reviewed studies presented environmental conservation strategies ([26], [23]). The remaining $2.57 \%$ of the studies reported the use of policies and good industrial practices. They are based on models such as preventive and corrective maintenance to avoid environmental impacts. The results indicate that there are few studies on environmental mitigation strategies of SMEs ([27]).

\section{B. Environmental Mitigation}

The results for criterion $\mathrm{C} 2$ (environmental mitigation approaches) revealed that the most used form of mitigation is the application of good practices, with their share being around $9.43 \%$ of the reviewed studies [28]. The application of environmental policies by SMEs represents around 3.57\% of the reviewed articles ([29]). About $1.29 \%$ of the reviewed documents referred to the Code of the Company-Related Personnel Behavior ([30]).

TABLE III

RESUlT OF THE SYSTEMATIC STUDY

\begin{tabular}{|c|c|c|c|c|}
\hline \multirow{2}{*}{$\begin{array}{l}\text { Research sub- } \\
\text { questions }\end{array}$} & \multirow[b]{2}{*}{ Criteria } & \multirow{2}{*}{$\begin{array}{l}\text { Possible } \\
\text { Answer }\end{array}$} & \multicolumn{2}{|c|}{ Result } \\
\hline & & & $\begin{array}{c}\text { Number } \\
\text { of studies }\end{array}$ & $\begin{array}{r}\% \text { of } \\
\text { studies }\end{array}$ \\
\hline \multirow{7}{*}{$\begin{array}{l}\text { RQ1 What } \\
\text { strategies are } \\
\text { used to mitigate } \\
\text { environmental } \\
\text { impacts? }\end{array}$} & \multirow{2}{*}{$\begin{array}{l}\mathrm{C} 1 \text { : Strategies for } \\
\text { mitigating } \\
\text { environmental } \\
\text { impacts }\end{array}$} & Conventional & 82 & $84 \%$ \\
\hline & & $\begin{array}{l}\text { Development } \\
\text { Model }\end{array}$ & 18 & $18 \%$ \\
\hline & \multirow{3}{*}{$\begin{array}{l}\text { C2: Approaches } \\
\text { to mitigate } \\
\text { environmental } \\
\text { impacts }\end{array}$} & Good practices & 66 & $67 \%$ \\
\hline & & Policies & 25 & $26 \%$ \\
\hline & & Behavior code & 9 & $9 \%$ \\
\hline & \multirow{2}{*}{$\begin{array}{l}\text { C3: } \\
\text { Environmental } \\
\text { care model }\end{array}$} & Private & 62 & $63 \%$ \\
\hline & & Community & 38 & $39 \%$ \\
\hline \multirow{2}{*}{$\begin{array}{l}\text { RQ2 What } \\
\text { source of } \\
\text { financing is } \\
\text { necessary for } \\
\text { industrial SMEs } \\
\text { to develop } \\
\text { ecological } \\
\text { initiatives? }\end{array}$} & \multirow{2}{*}{$\begin{array}{l}\text { C4: Financing } \\
\text { ecological } \\
\text { initiatives }\end{array}$} & Public & 12 & $12 \%$ \\
\hline & & Private & 88 & $90 \%$ \\
\hline \multirow{2}{*}{$\begin{array}{l}\text { RQ3 What is the } \\
\text { level of training } \\
\text { in the } \\
\text { environmental } \\
\text { matter for the } \\
\text { industrial SME } \\
\text { leadership? }\end{array}$} & \multirow{2}{*}{$\begin{array}{l}\text { C5: } \\
\text { Environmental } \\
\text { Management } \\
\text { Training }\end{array}$} & Planned & 52 & $53 \%$ \\
\hline & & Informal & 48 & $49 \%$ \\
\hline \multirow{5}{*}{$\begin{array}{l}\text { RQ4 What is the } \\
\text { level of } \\
\text { environmental } \\
\text { awareness and } \\
\text { knowledge of } \\
\text { the employees of } \\
\text { industrial SMEs? }\end{array}$} & \multirow{3}{*}{$\begin{array}{l}\text { C6: Employee } \\
\text { training }\end{array}$} & Needs & 49 & $50 \%$ \\
\hline & & Process & 31 & $32 \%$ \\
\hline & & Community & 20 & $20 \%$ \\
\hline & \multirow{2}{*}{$\begin{array}{l}\text { C7 Media } \\
\text { involved }\end{array}$} & Technological & 79 & $81 \%$ \\
\hline & & Normative & 21 & $21 \%$ \\
\hline
\end{tabular}

\section{Environmental care model}

The results for criterion C3 (environmental care model) revealed $8.86 \%$ of the reviewed studies and showed that some SMEs had developed an environmental care model ([31], [27]). On the other hand, the care model that involved the community is reflected in around $5.43 \%$ of the documents reviewed [26].

\section{Sources of ecological initiative funding}

The results for criterion $\mathrm{C} 4$ (green initiative financing) revealed around $1.71 \%$ of the reviewed studies indicating the support for SMEs rendered by the public sector. On the other hand, around $12.57 \%$ of the articles indicate that ecological initiatives are funded from private sources ([27], [32]).

\section{E. Environmental training}

The results for criterion C5 (Environmental training of managers) revealed about $7.43 \%$ of the reviewed studies, mentioning that SMEs have training plans ([27]). On the other hand, self-training or informal training of managers represent around $6.86 \%$.

\section{F. Level of employee training}

The results for criterion C6 (Training of employees) revealed that around $7 \%$ of the reviewed articles indicate that SMEs organize courses according to their environmental needs ([33]). $4.43 \%$ of the reviewed studies mentioned other aspects when environmental training is part of sustainable development processes in SMEs ([34]). $2.86 \%$ of the publications indicated that training was carried out jointly with the population ([35], [36]).

\section{G. Media}

The results for criterion C7 (Means involved) revealed around $11.29 \%$ of the reviewed documents indicating SMEs using technological resources in the environmental training of their employees ([37]). In 3\% of the articles, environmental training is based on the regulations and policies of SMEs ([38]).

\section{H. Threats to the validity}

The scope of the research questions, publication bias, data extraction, and misclassification are the main limitations of this research. The research question was limited to the impact of industrial SMEs. However, during the realization of this mapping, environmental mitigation strategies use good business practice models were identified.

In this type of research, positive results of the environmental impact caused by industrial SMEs are likely to be published [39]. Articles related to environmental strategies were chosen. The selected articles were compared with a simple of relevant research documents. It was not considered some other bibliographic sources such as Google Scholar or Wiley that could have affected the systematic mapping. The bibliographic search was carried out until December 2018. It was tried to reduce inaccuracy in data extraction and misclassification, with the help of three reviewers.

\section{CONCLUSION}

This article presents a systematic mapping study aimed at discovering how researchers and SMEs treat environmental impact. It was analyzed the evidence found in the 98 primary studies, consisting of publications elated to environmental 
mitigation, these steps allowed to elaborate the state of the art of this investigation. The answers given to our research questions helped identify the evidence of environmental mitigation as an essential focus in the current functioning of SMEs and their image as perceived by their clients and the community.

Society needs a decent environment to live in, and economic development must be in harmony with this need. It is as simple as reducing the consumption of non-renewable resources, using water efficiently, reusing and recycling objects and materials, and reducing the consumption of electricity, among other things, and each member of the business community can contribute to it.

For many years, environmental conservation by SMEs has not been considered a problem. However, the environmental legislation, application of clean technologies, implementation of quality management systems, and environmental management often mean a source of concern. The rules, which in principle should be voluntary, have become almost mandatory due to the demands of national and international markets. Now, SMEs must have technicians qualified in environmental matters, specialized people who propose practical, inexpensive, and simple solutions.

On the other hand, the size of the company ceases to be a constraint for sustainable business development, and many small or medium enterprises present successful experiences through the improvement of their production processes, innovation in products, or environmental policy to contribute to sustainable development competitively. In environmental terms, the problem involves a considerable challenge for everyone, from the largest multinationals to the smallest company. All of them are somehow related to environmental pollution. Undoubtedly, greater involvement of SMEs in environmental care is required, which may give rise to redefining objectives, establishing effective strategies, and using instruments to improve environmental compliance. The results achieved by this mapping study will help our research group to develop new research fronts on the environmental strategies of SMEs.

\section{REFERENCES}

[1] E. Gudynas, Ecología, economía y ética del Desarrollo Sostenible. Abya-Yala, 2003

[2] G. Gallopin, Sostenibilidad y desarrollo sostenible: un enfoque sistémico. Cepal, 2003.

[3] T. Pritvorova, B. Tasbulatova, and E. Petrenko, "Possibilities of blitz-psychograms as a tool for human resource management in the supporting system of hardiness of company," Entrep. Sustain. Issues, vol. 6 , no. 2, pp. 840-853, 2018 .

[4] P. Oriol, A. van Klink, and J. A. Rozo Grisales, Manual Para El Emprendimiento Sostenible. Academia de innovación para la sostenibilidad, 2011.

[5] E. A. Osadchy and E. M. Akhmetshin, "Integration of industrial and educational sphere in modernization of economic relations," J. Appl. Econ. Sci., vol. 10, no. 5, p. 35, 2015.

[6] E. M. Akhmetshin, E. I. Artemova, L. V. Vermennikova, R. A. Shichiyakh, N. A. Prodanova, and N. M. Kuchukova, "Management of investment attractiveness of enterprises: Principles, methods, organization," Int. J. Appl. Bus. Econ. Res., vol. 15, no. 23, pp. 71-82, 2017.

[7] G. Núñez, Promoting corporate social responsibility in small and medium enterprises in the Caribbean: survey results, vol. 3. United Nations Publications, 2008.

[8] K. H. Hofmann, G. Theyel, and C. H. Wood, "Identifying Firm Capabilities as Drivers of Environmental Management and
Sustainability Practices - Evidence from Small and Medium-Sized Manufacturers,” Bus. Strateg. Environ., vol. 21, no. 8, pp. 530-545, 2012.

[9] A. V. Strizhenok and D. S. Korelskiy, "Assessment of the anthropogenic impact in the area of tailings storage of the apatitenepheline ores," Pollut. Res., vol. 34, no. 4, pp. 809-811, 2015.

[10] E. Nybakk and R. Panwar, "Understanding instrumental motivations for social responsibility engagement in a micro-firm context," Bus. Ethics, vol. 24, no. 1, pp. 18-33, 2015.

[11] S. Brammer, S. Hoejmose, and K. Marchant, "Environmental Management in SMEs in the UK: Practices, Pressures and Perceived Benefits," Bus. Strateg. Environ., vol. 21, no. 7, pp. 423-434, 2012.

[12] O. Ortiz, F. Castells, and G. Sonnemann, "Sustainability in the construction industry: A review of recent developments based on LCA," Constr. Build. Mater., vol. 23, no. 1, pp. 28-39, 2009.

[13] J. A. Aragón-Correa, N. Hurtado-Torres, S. Sharma, and V. J. García-Morales, "Environmental strategy and performance in small firms: A resource-based perspective," J. Environ. Manage., vol. 86, no. 1 , pp. 88-103, 2008.

[14] J. Lepoutre and A. Heene, "Investigating the impact of firm size on small business social responsibility: A critical review," J. Bus. Ethics, vol. 67, no. 3 , pp. $257-273,2006$.

[15] N. A. Torugsa, W. O'Donohue, and R. Hecker, "Capabilities, Proactive CSR and Financial Performance in SMEs: Empirical Evidence from an Australian Manufacturing Industry Sector," J. Bus. Ethics, vol. 109, no. 4, pp. 483-500, 2012.

[16] C. Aragón Amonarriz and C. Iturrioz Landart, "Responsible family ownership in small- and medium-sized family enterprises: An exploratory study,” Bus. Ethics, vol. 25, no. 1, pp. 75-93, 2016.

[17] C. Van Hemel and J. Cramer, "Barriers and stimuli for ecodesign in SMEs," J. Clean. Prod., vol. 10, no. 5, pp. 439-453, 2002.

[18] T. M. I. Mahlia, T. J. Saktisahdan, A. Jannifar, M. H. Hasan, and H. S. C. Matseelar, "A review of available methods and development on energy storage; Technology update," Renew. Sustain. Energy Rev., vol. 33, pp. 532-545, 2014.

[19] G. Anggadwita and Q. Y. Mustafid, "Identification of Factors Influencing the Performance of Small Medium Enterprises (SMEs)," Procedia - Soc. Behav. Sci., vol. 115, pp. 415-423, 2014.

[20] D. L. Gadenne, J. Kennedy, and C. McKeiver, "An empirical study of environmental awareness and practices in SMEs," J. Bus. Ethics, vol. 84, no. 1, pp. 45-63, 2009.

[21] E. Akhmetshin, I. Morozov, A. Pavlyuk, A. Yumashev, N Yumasheva, and S. Gubarkov, "Motivation of personnel in an innovative business climate," Eur. Res. Stud. J., vol. 21, no. 1, pp. 352-361, 2018.

[22] S. Seuring and M. Müller, "From a literature review to a conceptual framework for sustainable supply chain management," J. Clean. Prod., vol. 16, no. 15, pp. 1699-1710, 2008.

[23] A. Azapagic, "Developing a framework for sustainable development indicators for the mining and minerals industry," J. Clean. Prod., vol. 12, no. 6, pp. 639-662, 2004.

[24] R. Nidumolu, C. K. Prahalad, and M. R. Rangaswami, "Why sustainability is now the key driver of innovation," Harv. Bus. Rev., vol. 87, no. 9, pp. 56-64, 2009.

[25] C. R. Carter, M. R. Hatton, C. Wu, and X. Chen, "Sustainable supply chain management: continuing evolution and future directions," Int. J. Phys. Distrib. Logist. Manag., vol. 50, no. 1, pp. 122-146, 2019.

[26] H. E. J. Bos-Brouwers, "Corporate sustainability and innovation in SMEs: evidence of themes and activities in practice," Bus. Strateg. Environ., vol. 19, no. 7, pp. 417-435, 2010.

[27] J. Klewitz and E. G. Hansen, "Sustainability-oriented innovation of SMEs: a systematic review," J. Clean. Prod., vol. 65, pp. 57-75, 2014.

[28] R. K. Singh, H. R. Murty, S. K. Gupta, and A. K. Dikshit, "An overview of sustainability assessment methodologies," Ecol. Indic., vol. 9, no. 2, pp. 189-212, 2009.

[29] H. Jenkins and N. Yakovleva, "Corporate social responsibility in the mining industry: Exploring trends in social and environmental disclosure," J. Clean. Prod., vol. 14, no. 3-4, pp. 271-284, 2006.

[30] M. J. Hutchins and J. W. Sutherland, "An exploration of measures of social sustainability and their application to supply chain decisions," J. Clean. Prod., vol. 16, no. 15, pp. 1688-1698, 2008.

[31] S. Seuring, "A review of modeling approaches for sustainable supply chain management," Decis. Support Syst., vol. 54, no. 4, pp. 15131520, 2013. 
[32] C. Labuschagne, A. C. Brent, and R. P. G. Van Erck, "Assessing the sustainability performances of industries," J. Clean. Prod., vol. 13, no. 4, pp. 373-385, 2005.

[33] R. Côté, A. Booth, and B. Louis, "Eco-efficiency and SMEs in Nova Scotia, Canada," J. Clean. Prod., vol. 14, no. 6-7, pp. 542-550, 2006.

[34] J. A. Del Brl'lio and B. Junquera, "A review of the literature on environmental innovation management in SMEs: implications for public policies," Technovation, vol. 23, no. 12, pp. 939-948, 2003.

[35] I. Martl'lin-Tapia, J. A. Aragón-Correa, and A. Rueda-Manzanares, "Environmental strategy and exports in medium, small and microenterprises," J. World Bus., vol. 45, no. 3, pp. 266-275, 2010.

[36] H. W. Chesbrough and M. M. Appleyard, "Open innovation and strategy," Calif. Manage. Rev., vol. 50, no. 1, pp. 57-76, 2007.
[37] J. K. Staniskis and Z. Stasiskiene, "Environmental management accounting in Lithuania: exploratory study of current practices, opportunities and strategic intents," J. Clean. Prod., vol. 14, no. 14, pp. $1252-1261,2006$.

[38] A. Howgrave-Graham and R. van Berkel, "Assessment of cleaner production uptake: method development and trial with small businesses in Western Australia," J. Clean. Prod., vol. 15, no. 8-9, pp. 787-797, 2007.

[39] S. Benito-Hernández, M. Platero-Jaime, and P. Esteban-Sánchez, "The influence of cooperative relations of small businesses on environmental protection intensity," Bus. Ethics, vol. 25, no. 4, pp. 416-439, 2016. 